BENTHAM OPEN
CrossMark
Content list available at: www.benthamopen.com/TOORTHJ/
DOI: $10.2174 / 1874325001610010339$

REVIEW ARTICLE

\title{
Prognosis Driven Rehabilitation After Rotator Cuff Repair Surgery
}

\author{
Dirk Kokmeyer ${ }^{1, *}$, Eric Dube ${ }^{2}$ and Peter J. Millett, ${ }^{3}$ \\ ${ }^{I}$ Maine Medical Partners, Orthopedic and Sports Medicine, South Portland, Maine, United States \\ ${ }^{2}$ Howard Head Sports Medicine, Silverthorne, Colorado, United States \\ ${ }^{3}$ The Steadman Clinic, Vail, Colorado, United States
}

Received: June 29, 2015

Revised: August 23, 2015

Accepted: February 01, 2016

\begin{abstract}
:
Background:

Rehabilitation after rotator cuff repair surgery has been the focus of several clinical trials in the past decade. Many illuminate new evidence with regard to the prognosis of structural and functional success after surgery.
\end{abstract}

\section{Methods:}

A selective literature search was performed and personal physiotherapeutic and surgical experiences are reported.

\section{Results:}

Post-operative rehabilitation parameters, namely the decision to delay or allow early range of motion after surgery, play a large role in the overall success after surgery. Using a prognosis driven rehabilitation program offers clinicians a means of prescribing optimal rehabilitation parameters while ensuring structural and functional success. This commentary aims to synthesize the evidence in a spectrum of prognostic factors to guide post-operative rehabilitation.

\section{Conclusion:}

The optimal rehabilitation program after rotator cuff repair surgery is debatable; therefore, we suggest using a spectrum of prognostic factors to determine a rehabilitation program suited to ensure structural and functional success, quickly and safely.

Keywords: Physical therapy, Protocol, Rehabilitation, Rotator cuff repair, Shoulder.

\section{INTRODUCTION}

A brief analysis of the US National Library of Medicine (Pubmed) citations specific to 'rotator cuff repair' showed a 380\% increase in citations from 2005-2015 compared to 1995-2005. This surge in attention to rotator cuff repair (RCR) surgery includes a significant number of papers focusing on rehabilitation and prognosis. The goal of RCR surgery is to restore the normal anatomy of the rotator cuff in order to reduce pain and restore function. Subsequently, the objective of the post-operative rehabilitation is to ensure the structural and functional success of surgery. Success, however, is based on numerous factors, including the symptom severity, tear size and retraction, fatty infiltration and muscle atrophy, failure of previous treatments, health status, and factors that affect outcome and healing. These factors constitute 432 possible combinations of factors, which the American Academy of Orthopedic Surgeons established in the appropriate use criteria for optimizing the management of full-thickness rotator cuff tears [1]. While the intent of research regarding the treatment of rotator cuff tears is to critically evaluate the efficacy of possible treatment options,

\footnotetext{
* Address correspondence to this author at the Maine Medical Partners, Orthopedics and Sports Medicine, 119 Gannett Drive, South Portland, Maine 04106, United States; E-mails: Kokmeyer@vvmc.com, dkokmeyer@mmc.org
} 
the exponential growth of emerging evidence can be daunting for a clinician to synthesize and interpret. Therefore, we aim to provide a synthesis of evidence regarding the prognostic factors leading to the structural and functional success of RCR surgery in this commentary. Secondarily, we aim to offer rehabilitation suggestions based on these prognostic factors.

\section{Structural Versus Functional Success}

Success after RCR surgery can be defined in two ways: functional and structural. Functional success refers to elements of patient satisfaction and quality of life. These factors are typically measured by outcome scores, namely the American Shoulder and Elbow Surgeons (ASES) score, the short or long form of the Disability of the Arm, Shoulder and Hand (DASH) score, the Western Ontario Rotator Cuff Index (WORC), the Constant-Murley score, the Single Assessment Numeric Evaluation (SANE), and the short forms 12 (SF-12) and 36 (SF-36). In general, these measures mesh constructs of pain, disability, and function as they relate upper extremity impairments and demands.

Structural success refers to the success of the surgical procedure in restoring rotator cuff anatomy, or, in simple terms, when the repair remains intact. Structural success is typically assessed using diagnostic ultrasound (US) and/or magnetic resonance imaging (MRI) and/or computed tomography arthrography (CTA) [2]. It would seem logical to infer that structural success will reduce impairments (i.e. ROM and strength), leading to functional success; however, functional success is often observed in patients with failed structural healing [3, 4].

In fact, the relationship between clinical outcomes and structural healing was the topic of a systematic review that concluded structural healing could not definitively predict better clinical outcomes [5]. This finding was the impetus to a prospective, multi-center clinical trial in which physical therapy was used as the initial treatment for patients with atraumatic rotator cuff tears [6]. Interestingly, a standard physical therapy program yielded $75 \%$ success with failure defined as the patient opting to undergo RCR surgery. Moreover, patients who elected to have surgery typically did so within the first 3 months of conservative management. These results indicate the importance of physical therapy at restoring function in the upper extremity in the presence of rotator cuff insufficiency. Physical therapy is especially important since regaining strength after certain RCRs is questionable, particularly larger tears with increased fatty infiltration [7, 8]. Therefore, physical therapists who treat patients who undergo RCR surgery should utilize a comprehensive strategy with structural and functional success in mind.

\section{Structural Success, Tissue Healing and Early Motion}

Normal soft tissue healing after tendon repair follows a three-stage process - initial inflammation, fibroblastic (proliferative) activity, and remodeling [9, 10]. During the first stage of inflammation, vascular permeability increases and inflammatory cells carrying cytokines and growth factors infiltrate the area [9]. This stimulates fibroblastic cellular proliferation, yielding haphazard type I and III collagen formation at the tendon-bone junction. With time and appropriate loading, more type I collagen is expressed and the fiber orientation transitions to a more parallel orientated, stronger layout [5, 11 - 13]. Small, full-thickness tears in the rotator cuff tend to follow a normal healing process, whereas larger tears exhibit fewer fibroblasts and limited cell proliferation, thus reducing the potential for physiologic healing [14].

Large tear repairs tend to re-tear between 3-26 weeks after surgery [13]. This broad time frame coincides with the variable healing time of the proliferative and remodeling phases, both of which are negatively affected by local and systemic confounding factors [9, 10, 15]. Conversely, Boileau et al. [16] concluded that isolated supraspinatus tears led to superior healing at 29 months follow-up. They also found that average shoulder forward elevation strength was higher in patients with confirmed tendon healing versus those with a persistent defect. This discrepancy in structural healing left researchers to question the timing of range of motion after surgery is performed.

Several animal model studies in the past decade have focused on comparing early to delayed motion after RCR surgery in the initial phase of rehabilitation [17 - 19]. The primary outcome of these studies is structural success. One such study compared two weeks of absolute immobilization (continuous immobilization) to relative immobilization (immobilization with PROM) in rodents with acute supraspinatus repairs [17]. The rodents were then "remobilized" using a gradual progression of cage activity to treadmill running. At the $6^{\text {th }}$ post-operative week, mechanical and histologic testing measures were not statistically different among the groups. Although ROM improvements favored the immobilization group, the authors concluded that "detrimental" effects occur with early range of motion after RCR surgery. A similar study compared cage activity to a treadmill running protocol after 2 weeks of immobilization [18]. At the $12^{\text {th }}$ post-operative week, rodents in the exercise group demonstrated decreased ROM and inferior mechanical and 
histological tendon quality. These results are not surprising because they exhibit a scenario of tissue overloading. When a rehabilitation program more analogous to a human RCR protocol was studied, Zhang et al. [19] found no differences in biomechanical, structural or MRI signaling in RCR surgeries performed on rabbits when relative immobilization was compared to absolute immobilization for 6 weeks. In comparison, rodents were exposed to early closed kinetic chain activity. Closed kinetic chain activity is considered a high-level strengthening activity in published rehabilitation protocols [20 - 22] and typically reserved for later phases of rehabilitation.

The results of the aforementioned animal studies prompted several researchers to investigate early versus delayed rehabilitation programs in human subjects. Researchers sought to answer the following clinical questions: does early range of motion in RCRs lead to structural failure? Are functional outcomes better with earlier or delayed motion programs? And, does delayed motion lead to shoulder stiffness? The deluge of clinical studies influenced recent systematic reviews, some with meta-analyses [23 - 26]. Briefly, Chang et al. [23] proposed an algorithm suggesting that patients presenting with risk factors predictive of structural failure should undergo a delayed motion program, and patients with risk factors suggestive of stiffness but not structural failure may be better suited for an early ROM program. Lastly, the authors proposed that patients without healing risk factors follow a delayed program due to costsavings; these findings should be interpreted with caution because a cost-analysis comparing the impact of early versus delayed motion does not exist in the literature.

Kluczynski et al. [24] recently performed two systematic reviews with meta-analyses of Level 1 and Level 1-4 studies. The pooled data favored early PROM (initiated within 1 week of surgery) for $>1 \mathrm{~cm}$ tears and delayed motion (defined as beginning 3-6 weeks after surgery) for $>5 \mathrm{~cm}$ tears. No significant differences in re-tears were found in tears $>3 \mathrm{~cm}, 3-5 \mathrm{~cm}$, and $>3 \mathrm{~cm}$, regardless of repair type, leaving the decision to allow early motion to clinical reasoning and prognostic factors. Tears $>5 \mathrm{~cm}$ demonstrated greater risk of tearing (RR: 2.82 ). Using similar methodology, the same group compared early versus delayed active ROM and found no difference in re-tear rates in tears $>3 \mathrm{~cm}$ with doublerow suture anchor techniques; however transosseous and single-row anchor techniques had significantly higher re-tear rates [25]. Tears exceeding $3 \mathrm{~cm}$ had higher rates of re-tears leaving the authors to conclude that active ROM should be delayed until 6 weeks after surgery.

\section{Prognostic Factors of Functional and Structural Success}

Prognosis is a means of predicting the course of a disease and prognostic factors are characteristics associated with the outcome of a disease [27]. In terms of RCR surgery, prognostic factors are a means of determining the structural and functional success of surgery. The type of surgical procedure and therapy are two factors among a long list of factors that affect one another in the overall success of surgery. An evaluation-based approach to rehabilitation has been recommended as a means of ensuring success [21]. Part of this approach is based on using prognostic factors. We recommend using these factors in a prognostic spectrum to guide the post-operative management of patients who undergo RCR surgery. Table 1 outlines several prognostic factors previously defined by evidence that drive the functional and structural success of RCR surgery. Patients with specific risk factors negatively affecting the overall surgical success should be directed to a conservative rehabilitation program; whereas those patients with factors associated with better healing potential and functional success may undergo a more rapid progression of postoperative rehabilitation. Table 2 outlines our recommended rehabilitation parameters, which have been outlined in more detail in a previous publication [22].

Age is a primary factor affecting structural success of RCR surgery. Several studies show that patients younger than approximately 50 years of age demonstrate better tendon healing than those above the age of 60-65 years of age [28 32]. Increasing age is also associated with poorer functional outcomes [32, 33] and longer recovery times [32]. As age increases, typically so does tear size. Larger tears are associated with higher failure rates [29 - 31], recovery greater than six months [13, 32], and greater tendon retraction [34]. Larger, atraumatic tears tend to exhibit greater fatty infiltration (FI) and muscle atrophy (MA) [35 - 37]. Various methods are used to determine the degree of FI and MA [35 - 39], however the most commonly utilized method is the Goutallier scale, which classifies minimal FI and MA as stage zero and severe as stage four [35]. Repair failure reaches $100 \%$ in tears associated with greater than stage 2 FI and MA, whereas tears with less than stage 1 FI and MA achieve greater than $92 \%$ healing [28]. Finally, larger tears appear to have poorer histological quality with decreased propensity for healing [14].

Factors extrinsic to the rotator cuff, yet affect healing and functional success include bone mineral density (BMD), smoking, diabetes mellitus (DM), and obesity. Osteopenia (BMD: $-1--2.5$ ) and osteoporosis (BMD > -2.5) have an increased risk of structural failure, which is likely due to decreased pull-out strength of anchor fixations [4]. Nicotine 
propogates vasoconstriction to rotator cuff tendons further reducing blood flow to an already hypovascular region [40]. This leads to delayed healing potential, which has been observed in controlled rodent experiments [41]. Furthermore, tear size and severity is associated with the number of cigarettes smoked in a lifetime [40], small improvements in functional outcomes and increased post-operative pain [42]. Although DM does not directly affect the quality of healing [30], the presence of DM increases the risk of post-operative stiffness [43] and leads to poorer functional outcomes [33]. Therefore, an early ROM may be more appropriate for patients with DM. Patients with a body mass index of $>30$ are considered obese. These patients are prone to longer hospital stays after RCR surgery, higher failure rates, poorer outcome scores and limited ROM [44].

Table 1. Prognostic Spectrum. Shoulder prognostic spectrum to recommend the type of post-operative rehabilitation program after RCR surgery.

\begin{tabular}{|c|c|c|c|}
\hline & Moderate & Intermediate & Conservative \\
\hline Age & $<50$ & $50-60$ & $>60$ \\
\hline BMD & $>-1$ & -2.4 to -1 (penia) & $<-2.5$ (porosis) \\
\hline FI + atrophy & stage 0 & stage $0-1$ & stage $1-2$ \\
\hline DM & + & + & - \\
\hline BMI & $<25$ & $25-30$ & $>30$ \\
\hline Smoker & - & - & + \\
\hline Tear size & $\begin{array}{l}\text { partial -small } \\
\text { (1 tendon) }\end{array}$ & $\begin{array}{l}\text { Small-medium } \\
\text { (1-2 tendon) }\end{array}$ & $\begin{array}{c}\text { Large-Massive } \\
(2+\text { tendons })\end{array}$ \\
\hline Retraction & none & in-between & $>$ Glenoid \\
\hline Tissue Quality & Good & Fair & Poor \\
\hline Pre-op Strength & Good & Fair & Poor \\
\hline
\end{tabular}

(BMD: Bone Mineral Density, FI: Fatty Infiltration, DM: Diabetes Mellitis, BMI: Body Mass Index).

Table 2. Prognosis-based Rehabilitation. Rehabilitation parameters for each post-operative rehabilitation protocol.

\begin{tabular}{|c|c|c|c|}
\hline & Moderate & Intermediate & Conservative \\
\hline Sling & comfort-2 weeks & $4-6$ weeks & begin: $4-6$ weeks \\
\hline PROM & begin: Immediate & begin: 0-4 week & 30 ER, 90 ABD, 120 FE \\
& FPROM & FPROM: 6-8 weeks \\
\hline AROM & $0-2$ weeks 90 ABD, 120 FE & $6-8$ weeks \\
\hline Strength & FPROM: 4-6 weeks & $4-6$ weeks & $10-12$ weeks \\
\hline
\end{tabular}

(PROM: passive range of motion, AROM: Active Range of Motion, FPROM: full passive range of motion, ER: external rotation, ABD: abduction, FE: forward elevation).

There are also pre-operative factors that affect functional success after RCR surgery. These are factors that can be influenced pre-operatively with a rehabilitation program [11]. Lapner et al. [45] determined that pre-operative strength was the best predictor of post-operative strength at the $12^{\text {th }}$ post-operative month in a prognostic study. Pre-operative stiffness is suggested as a negative predictor of functional outcomes at 6 months after surgery, even when a concomitant capsular release was performed [32]. This may explain why post-operative patients who participate in higher levels of sporting activities score higher on physical quality of life components of the SF-36 [33]. Given that a rehabilitation program is successful at improving functional outcomes in the presence of rotator cuff insufficiency [6], these factors warrant pre-operative physical therapy when ROM and strength impairments are identified. Pre-operative treatment of patients with low BMD and BMI should be considered to improve the probability of functional and structural success.

\section{Initial Phase of Rehabilitation: Shoulder Mobility and Graded Manual Therapy}

Restoration of shoulder complex mobility after any type of RCR is the initial goal in the initial phase of rehabilitation [20 - 22], but determining the right timing and progression of therapy can be a challenge. The degree of post-operative pain, muscle guarding, swelling and scar tissue formation vary after RCR surgery, suggesting treatments should be case-specific. It is also critical to continuously monitor a patient's tolerance to ROM components, as shoulder pain during or after treatment can help guide therapy. Kelly, McClure and Leggin [43] proposed an irritability classification for treatment of adhesive capsulitis, which we recommend as a guide to dose RCR rehabilitation (see Table 3). The authors identified three levels of irritability - high, moderate, and low. The degree of irritability should match the load, duration and frequency of interventions applied to the patient's shoulder. For instance, patients with 
high irritability should be prescribed interventions that do not increase the level of irritability. This includes low grade mobilizations and ROM exercises within pain tolerance. Patients with low irritability may be prescribed mobilizations and ROM exercises to end-range. Load, frequency and duration.

Table 3. Adapted from: Kelley MJ, McClure PW, Leggin BG. Frozen Shoulder: Evidence and a Proposed Model Guiding Rehabilitation. J Orthop Sports Phys Ther. 2009; 39(2):135-148.

\begin{tabular}{|c|c|c|}
\hline \multicolumn{2}{|c|}{ Low } & Moderate \\
\hline Low Pain & Moderate Pain & High Pain \\
\hline No resting or night pain & Intermittent night or rest pain & Consistent night or rest pain \\
\hline Low disability on DASH or ASES & Moderate disability on DASH or ASES & High Disability on DASH or ASES \\
\hline Minimal pain at end ROM with overpressure & Pain at end ROM & Pain prior to end ROM \\
\hline AROM same as PROM & AROM similar to PROM & AROM less than PROM secondary to pain \\
\hline
\end{tabular}

\section{Glenohumeral Arthrokinematics}

Glenohumeral joint $(\mathrm{GHJ})$ capsule and ligamentous mobility play an important role in the static and dynamic positioning of the humeral head in the glenoid concavity. Restoration of arthrokinematic mobility should occur to set the stage for non-compensatory, pain-free osteokinematic ROM. Deficits with inferior capsular mobility is associated with pain and increased superior humeral head migration [46], rotator cuff weakness [47], and subacromial impingement [47 - 49]. Evidence also suggests that superior humeral head migration has been associated with attritional damage of the primary stabilizers of the glenohumeral joint, and can contribute to chondral degeneration [50].

Manual therapy techniques are used to restore joint arthrokinematics. The irritability classification can further be applied to dosing of manual therapy techniques previously discussed. Muraki et al. [51] found that there was gap formation within a repaired supraspinatus with grades II and III inferior gliding with the arm at 0 degrees. Their study indicated that translatory glides can be safely performed with the arm positioned at 30 degrees of abduction if the repair was performed at 0 degrees abduction [51]. With time, and as pain decreases and disability scores improve, graded mobilizations can increase in intensity and duration, and progress by mobilizing the glenohumeral joint in the hypomobile, closed-packed position (abduction and external rotation). Johnson et al. [52] found that limitations with external rotation can be effectively addressed with posteriorly directed glides at end-range abduction and external rotation [52]. Inferior capsular mobilizations can be implemented to normalize the inferior head gliding, which occurs during shoulder elevation - abduction and flexion.

\section{Scapular Kinesis}

Altered scapular positioning and kinematics have been associated with shoulder impingement, pain, stiffness, rotator cuff tendonopathy, rotator cuff tears, glenohumeral instability, and adhesive capsulits [46, 53, 54]. Scapular mobility should be assessed, both statically and dynamically, at the scapulothoracic (ST), acromiocalvicular (AC), and sternoclavicular (SC) joints. Hypomobililty or hypermobility at just one aspect of the shoulder coupling can affect the quantity and quality of shoulder movement, specifically with elevation [46, 53, 54] Restoration of normal scapular upward rotation mobility, and stability with concurrent humeral elevation, is an important step towards normalizing the synchronous relationship of GH and ST ROM. Decreased upward rotation of the scapula has been identified with individuals who have shoulder pain versus those who do not $[47,53]$.

Lawrence et al. [53] found that symptomatic shoulder pain was associated with reduced SC posterior rotation and elevation during both humeral abduction and scapular plane elevation. Because there is no muscle directly acting on this joint, SC motion occurrs as a result of scapular upward rotation and subsequent tension through the AC joint and coracoclavicular ligaments $[51,53]$. This research supports the necessity of increased focus on SC and AC joint mobilization to restore the quantity and efficiency of the scapular coupling, but one must also incorporate dynamic strengthening of the muscles that act on the scapular force couple - upper/middle/lower trapezius, rhomboid major/minor, levator scapula, and serratus anterior. If ST kinematics are not normalized, shoulder impingement syndrome may occur or re-occur, and there can be an increase in the relative risk or cuff re-tearing [47, 54, 55].

Promoting proper scapular kinesis can be trained very early in rehab. Isometric scapular retraction can begin in standing or sitting, and can be progressed to the prone position. Scapular elevation compensation with overhead ROM can be secondary to GH or ST joint hypomobility, cuff weakness, pain, and/or a neuromuscular deficit. A therapist's use of tactile cuing at the interscapular muscles can be useful to maximize muscle activation and cue for specific 
scapular motion, such as recruitment of the lower trapezius when upper trapezius activity is dominant. Early exercises include manually resisted scapular isometrics and active movements that avoid glenohumeral and cuff activity. These may be progressed to exercises against gravity in the active phase, where synchronous and rhythmic motion between the ST and GH joint should be the focus.

\section{Early Strength Phase: Muscle Physiology of the Rotator Cuff}

The rotator cuff is comprised of four muscle tendon units - the supraspinatus, infraspinatus, teres minor, and subscapularis. At the insertions, the tendons of these muscles fuse together to form a continuous structure [9]. The cuff is then defined by two surfaces - the bursal and articular surfaces, with the bursal surface being reinforced by the coracohumeral ligament anterosuperiorly, and the articular side covered by the synovialized joint capsule lining. The construct of the GH joint is designed to be a highly mobile segment. With that, the cuff muscles are positioned on the scapular platform to provide dynamic support through short lever arms. Together, the axial force couple of the subscapularis and infraspinatus/teres minor when contracted creates a compression force that centers the humeral head in the glenoid concavity. In a healthy shoulder, the cuff muscles dynamically maintain the humeral head compressed and centered during elevation, as the humeral head glides inferiorly and rolls posteriorly or anteriorly. Restoring the dynamic balance of the rotator cuff strength is imperative to reduce the risk of pathological GH mechanics and subsequent subacromial impingement or cuff tearing.

Initiation of the strength training is a component of the second phase of RCR, and the timing remains variable based on prognostic driven factors [22]. Criteria for progression into this phase is adequate PROM and non-compensated GH and ST AROM [21]. Surrounding, non-repaired rotator cuff muscles should also be taken into consideration when initiating strength training; subscapularis, infraspinatus and teres minor muscle support affects the static and dynamic humeral head position within the glenoid $[9,47$.$] Increasing the support from the surrounding cuff musculature should$ decrease the direct stress/strain on a repaired supraspinatus, which may increase the short- and long-term survivorship of the soft tissue.

Strength training should focus on endurance, using high repetition, low resistance parameters. Rhythmic stabilization, a form of open chain isometric training, can also be performed with gradually increasing pressure and duration of multidirectional holds to stimulate co-contractions at the pectoral girdle [21, 22]. Internal and external rotation strengthening can be performed using resistance bands in standing, or in side lying with hand weights. Supraspinatus muscle activation is safely targeted with a full-can motion [47]. After good muscle activation and endurance is established, strength and power oriented training through higher resistance can be initiated using a periodization format to load the healing tendon-bone interface and stimulate healthy remodeling $[9,10,56]$.

Handheld dynamometry is a helpful tool to determine a limb symmetry index (LSI), which can then be helpful when establishing a strength goal. When evaluating patient's readiness to return to sport, having a $90 \%$ strength index or greater is a good baseline goal, but a further evaluation of functional movement patterns and dynamic endurance should be performed on both sides to ensure that even the uninvolved side is "healthy" and free from dysfunctional movement patterns and muscle imbalances. The sport of interest should also be scrutinized. Overhead throwing sports will require more shoulder rotation mobility, strength and eccentric control, depending on the extremity dominance. For example, golf will require specific mobility and stability requirements at the shoulder girdle, otherwise compensation at other segments may occur [57]. Whatever the sport may be, an integrated approach must be taken to address core strength and functional shoulder mobility and strength capacity. Regardless, patients should use a slow re-introduction back into a sport using irritability as a guide his or her progression.

\section{CONCLUSION}

Predicting surgical outcomes using pre-, intra- and post-operative prognostic factors has been a topic of interest in the literature. Functional shoulder recovery after RCR surgery is the terminal goal, but there is no one surgical technique or protocol that has been established to address each combination of prognostic factors. The aim of this commentary was to provide post-operative rehabilitation considerations for the treatment of rotator cuff repairs. We suggest using a spectrum of prognostic factors to determine a rehabilitation program suited to ensure structural and functional success, quickly and safely.

\section{ABBREVIATIONS}

ABD - 


\begin{tabular}{|c|c|c|}
\hline $\mathrm{AC}-$ & $=$ & Acromioclavicular \\
\hline ASES - & $=$ & American Shoulder and Elbow Surgeons \\
\hline BMD - & $=$ & Bone Mineral Density \\
\hline CTA - & $=$ & Computed Tomography Arthrography \\
\hline DASH - & $=$ & Disability of the Arm, Shoulder and Hanc \\
\hline DM - & $=$ & Diabetes Mellitis \\
\hline ER - & $=$ & External rotation \\
\hline $\mathbf{F E}-$ & $=$ & Forward elevation \\
\hline FI - & $=$ & Fatty Infiltration \\
\hline FPROM - & $=$ & Full passive range of motin \\
\hline GH - & $=$ & Glenohumeral \\
\hline MA - & $=$ & Muscle Atrophy \\
\hline MRI - & $=$ & Magnetic Resonance Imaging \\
\hline PROM - & $=$ & Passive range of motion \\
\hline RCR - & $=$ & Rotator Cuff Repair \\
\hline ROM - & $=$ & Range of Motion \\
\hline $\mathbf{R R}-$ & $=$ & Risk Ratio \\
\hline SANE - & $=$ & Single Assessment Numeric Evaluation \\
\hline SF-12- & $=$ & Short Form 12 \\
\hline SF-36 - & $=$ & Short Form 36 \\
\hline ST - & $=$ & Scapulothoracic \\
\hline STAR - & $=$ & Staged approach for Rehabilitation \\
\hline US - & $=$ & Ultrasound \\
\hline WORC - & $=$ & Western Ontario Rotator Cuff Index \\
\hline SC - & $=$ & Sternoclavicular \\
\hline
\end{tabular}

\section{AUTHOR DISCLOSURES}

This research was supported by the Vail Valley Medical Center, Howard Head Sports Medicine and Steadman Philippon Research Institute, which is a 501(c)(3) non-profit institution supported financially by private donations and corporate support from the following entities: Smith \&amp; Nephew Endoscopy, Inc., Arthrex, Inc., Ossur Americas, Inc., and Vail Valley Medical Center. This work was not supported directly by outside funding or grants. Peter J. Millett has received from Arthrex something of value (exceeding the equivalent of US\$500) not related to this manuscript or research. He is a consultant and receives royalties from Arthrex. He receives royalties from Springer publishing and has stock options and stock options in Game Ready and VuMedi. He is also a consultant for Myos Inc.

\section{CONFLICT OF INTEREST}

The authors confirm that this article content has no conflict of interest.

\section{ACKNOWLEDGEMENTS}

The authors would like to thank Kim-Lyons Mitchell of the Vail Valley Medical Center for her ongoing assistance and Melissa Strzelinski for her assistance with this manuscript.

\section{REFERENCES}

[1] Sanders JO, Keith MW, Murray J, Pezold R. The American Academy of Orthopaedic Surgeons appropriate use criteria on optimizing the management of full-thickness rotator cuff tears. J Bone Joint Surg Am 2014; 96(8): 683-4. [http://dx.doi.org/10.2106/JBJS.M.01541] [PMID: 24740665]

[2] Gerber C, Fuchs B, Hodler J. The results of repair of massive tears of the rotator cuff. J Bone Joint Surg Am 2000; 82(4): 505-15. [PMID: 10761941]

[3] Oh JH, Kim SH, Ji HM, Jo KH, Bin SW, Gong HS. Prognostic factors affecting anatomic outcome of rotator cuff repair and correlation with functional outcome. Arthroscopy 2009; 25(1): 30-9. 
[4] Chung SW, Oh JH, Gong HS, Kim JY, Kim SH. Factors affecting rotator cuff healing after arthroscopic repair: osteoporosis as one of the independent risk factors. Am J Sports Med 2011; 39(10): 2099-107. [http://dx.doi.org/10.1177/0363546511415659] [PMID: 21813440]

[5] Slabaugh MA, Nho SJ, Grumet RC, et al. Does the literature confirm superior clinical results in radiographically healed rotator cuffs after rotator cuff repair? Arthroscopy 2010; 26(3): 393-403.

[6] Kuhn JE, Dunn WR, Sanders R, et al. Effectiveness of physical therapy in treating atraumatic full-thickness rotator cuff tears: a multicenter prospective cohort study. J Shoulder Elbow Surg 2013; 22(10): 137-9.

[7] Rokito AS, Zuckerman JD, Gallagher MA, Cuomo F. Strength after surgical repair of the rotator cuff. J Shoulder Elbow Surg 1996; 5(1): 12-7. [PMID: 8919437]

[8] Gladstone JN, Bishop JY, Lo IK, Flatow EL. Fatty infiltration and atrophy of the rotator cuff do not improve after rotator cuff repair and correlate with poor functional outcome. Am J Sports Med 2007; 35(5): 719-28. [http://dx.doi.org/10.1177/0363546506297539] [PMID: 17337727]

[9] Huegel J, Williams AA, Soslowsky LJ. Rotator cuff biology and biomechanics: a review of normal and pathological conditions. Curr Rheumatol Rep 2015; 17(1): 476.

[http://dx.doi.org/10.1007/s11926-014-0476-x] [PMID: 25475598]

[10] Thomopoulos S, Parks WC, Rifkin DB, Derwin KA. Mechanisms of tendon injury and repair. J Orthop Res 2015; 33(6): 832-9. [http://dx.doi.org/10.1002/jor.22806] [PMID: 25641114]

[11] Fermont AJ, Wolterbeek N, Wessel RN, Baeyens JP, de Bie RA. Prognostic factors for successful recovery after arthroscopic rotator cuff repair: a systematic literature review. J Orthop Sports Phys Ther 2014; 44(3): 153-63. [http://dx.doi.org/10.2519/jospt.2014.4832] [PMID: 24450368]

[12] Iannotti JP, Deutsch A, Green A, et al. Time to failure after rotator cuff repair: a prospective imaging study. J Bone Joint Surg Am 2013; 95(11): 965-71. [http://dx.doi.org/10.2106/JBJS.L.00708] [PMID: 23780533]

[13] Miller BS, Downie BK, Kohen RB, et al. When do rotator cuff repairs fail? Serial ultrasound examination after arthroscopic repair of large and massive rotator cuff tears. Am J Sports Med 2011; 39(10): 2064-70. [http://dx.doi.org/10.1177/0363546511413372] [PMID: 21737833]

[14] Matthews TJ, Hand GC, Rees JL, Athanasou NA, Carr AJ. Pathology of the torn rotator cuff tendon. Reduction in potential for repair as tear size increases. J Bone Joint Surg Br 2006; 88(4): 489-95. [http://dx.doi.org/10.1302/0301-620X.88B4.16845] [PMID: 16567784]

[15] Thomopoulos S, Williams GR, Soslowsky LJ. Tendon to bone healing: differences in biomechanical, structural, and compositional properties due to a range of activity levels. J Biomech Eng 2003; 125(1): 106-13. [http://dx.doi.org/10.1115/1.1536660] [PMID: 12661203]

[16] Boileau P, Brassart N, Watkinson DJ, Carles M, Hatzidakis AM, Krishnan SG. Arthroscopic repair of full-thickness tears of the supraspinatus: does the tendon really heal? J Bone Joint Surg Am 2005; 87(6): 1229-40. [http://dx.doi.org/10.2106/JBJS.D.02035] [PMID: 15930531]

[17] Peltz CD, Dourte LM, Kuntz AF, et al. The effect of postoperative passive motion on rotator cuff healing in a rat model. J Bone Joint Surg Am 2009; 91(10): 2421-9. [http://dx.doi.org/10.2106/JBJS.H.01121] [PMID: 19797578]

[18] Peltz CD, Sarver JJ, Dourte LM, Wurgler-Hauri CC, Williams GR, Soslowsky LJ. Exercise following a short immobilization period is detrimental to tendon properties and joint mechanics in a rat rotator cuff injury model. J Orthop Res 2010; 28(7): 841-5. [http://dx.doi.org/10.1002/jor.21059] [PMID: 20058271]

[19] Zhang S, Li H, Tao H, et al. Delayed early passive motion is harmless to shoulder rotator cuff healing in a rabbit model. Am J Sports Med 2013; 41(8): 1885-92.

[http://dx.doi.org/10.1177/0363546513493251] [PMID: 23845402]

[20] Ghodadra NS, Provencher MT, Verma NN, Wilk KE, Romeo AA. Open, mini-open, and all-arthroscopic rotator cuff repair surgery: indications and implications for rehabilitation. J Orthop Sports Phys Ther 2009; 39(2): 81-9. [http://dx.doi.org/10.2519/jospt.2009.2918] [PMID: 19194025]

[21] Millett PJ, Wilcox RB III, O’Holleran JD, Warner JJ. Rehabilitation of the rotator cuff: an evaluation-based approach. J Am Acad Orthop Surg 2006; 14(11): 599-609.

[http://dx.doi.org/10.5435/00124635-200610000-00002] [PMID: 17030593]

[22] van der Meijden OA, Westgard P, Chandler Z, Gaskill TR, Kokmeyer D, Millett PJ. Rehabilitation after arthroscopic rotator cuff repair: current concepts review and evidence-based guidelines. Int J Sports Phys Ther 2012; 7(2): 197-218. [PMID: 22530194]

[23] Chang KV, Hung CY, Han DS, Chen WS, Wang TG, Chien KL. Early versus delayed passive range of motion exercise for arthroscopic rotator cuff repair: A meta-analysis of randomized controlled trials. Am J Sports Med 2015; 43(5): 1265-73.

[PMID: 25143489] 
[24] Kluczynski MA, Nayyar S, Marzo JM, Bisson LJ. Early versus delayed passive range of motion after rotator cuff repair: A systematic review and meta-analysis. Am J Sports Med 2015; 43(8): 2057-63. [PMID: 25296646]

[25] Kluczynski MA, Isenburg MM, Marzo JM, Bisson LJ. Does early versus delayed active range of motion affect rotator cuff healing after surgical repair? A systematic review and meta-analysis. Am J Sports Med 2015; 44(3): 7855-91. [http://dx.doi.org/10.1177/0363546514552802] [PMID: 25943112]

[26] Denard PJ, Ladermann A, Burkhart SS. Prevention and management of stiffness after arthroscopic rotator cuff repair: systematic review and implications for rotator cuff healing. Arthroscopy $2011 ; 27(6): 842-8$.

[27] Fletcher RH, Fletcher SW, Fletcher GS. Clinical Epidemiology: The Essentials. $5^{\text {th }}$ ed.. Wolters Kluwer Health/Lippincott Williams \& Wilkins 2012

[28] Cho NS, Rhee YG. The factors affecting the clinical outcome and integrity of arthroscopically repaired rotator cuff tears of the shoulder. Clin Orthop Surg 2009; 1(2): 96-104.

[http://dx.doi.org/10.4055/cios.2009.1.2.96] [PMID: 19885061]

[29] Gulotta LV, Nho SJ, Dodson CC, et al. Prospective evaluation of arthroscopic rotator cuff repairs at 5 years: part II--prognostic factors for clinical and radiographic outcomes. J Shoulder Elbow Surg 2011; 20(6): 941-6.

[30] Le BT, Wu XL, Lam PH, Murrell GA. Factors predicting rotator cuff retears: an analysis of 1000 consecutive rotator cuff repairs. Am J Sports Med 2014; 42(5): 1134-42.

[http://dx.doi.org/10.1177/0363546514525336] [PMID: 24748610]

[31] Wu XL, Briggs L, Murrell GA. Intraoperative determinants of rotator cuff repair integrity: an analysis of 500 consecutive repairs. Am J Sports Med 2012; 40(12): 2771-6. [http://dx.doi.org/10.1177/0363546512462677] [PMID: 23104609]

[32] Manaka T, Ito Y, Matsumoto I, Takaoka K, Nakamura H. Functional recovery period after arthroscopic rotator cuff repair: is it predictable before surgery? Clin Orthop Relat Res 2011; 469(6): 1660-6. [http://dx.doi.org/10.1007/s11999-010-1689-6] [PMID: 21107925]

[33] Chung SW, Park JS, Kim SH, Shin SH, Oh JH. Quality of life after arthroscopic rotator cuff repair: evaluation using SF-36 and an analysis of affecting clinical factors. Am J Sports Med 2012; 40(3): 631-9. [http://dx.doi.org/10.1177/0363546511430309] [PMID: 22190415]

[34] Davidson J, Burkhart SS. The geometric classification of rotator cuff tears: a system linking tear pattern to treatment and prognosis. Arthroscopy 2010; 26(3): 417-24. [http://dx.doi.org/10.1016/j.arthro.2009.07.009] [PMID: 20206053]

[35] Goutallier D, Postel JM, Bernageau J, Lavau L, Voisin MC. Fatty muscle degeneration in cuff ruptures. Pre- and postoperative evaluation by CT scan. Clin Orthop Relat Res 1994; (304): 78-83. [PMID: 8020238]

[36] Warner JJ, Higgins L. Diagnosis and treatment of anterosuperior rotator cuff tears. J Shoulder Elbow Surg 2001; 10(1): 37-46. [PMID: 11182734]

[37] Rulewicz GJ, Beaty S, Hawkins RJ, Kissenberth MJ. Supraspinatus atrophy as a predictor of rotator cuff tear size: an MRI study utilizing the tangent sign. J Shoulder Elbow Surg 2013; 22(6): e6-e10

[38] Millett PJ, Schoenahl JY, Allen MJ, Motta T, Gaskill TR. An association between the inferior humeral head osteophyte and teres minor fatty infiltration: evidence for axillary nerve entrapment in glenohumeral osteoarthritis. J Shoulder Elbow Surg 2013; 22(2): 215-21.

[39] Chung SW, Kim SH, Tae SK, Yoon JP, Choi JA, Oh JH. Is the supraspinatus muscle atrophy truly irreversible after surgical repair of rotator cuff tears? Clin Orthop Surg 2013; 5(1): 55-65. [http://dx.doi.org/10.4055/cios.2013.5.1.55] [PMID: 23467404]

[40] Carbone S, Gumina S, Arceri V, Campagna V, Fagnani C, Postacchini F. The impact of preoperative smoking habit on rotator cuff tear: cigarette smoking influences rotator cuff tear sizes. J Shoulder Elbow Surg 2012; 21(1): 56-60. [http://dx.doi.org/10.1016/j.jse.2011.01.039] [PMID: 21524922]

[41] Galatz LM, Silva MJ, Rothermich SY, Zaegel MA, Havlioglu N, Thomopoulos S. Nicotine delays tendon-to-bone healing in a rat shoulder model. J Bone Joint Surg Am 2006; 88(9): 2027-34. [http://dx.doi.org/10.2106/JBJS.E.00899] [PMID: 16951120]

[42] Mallon WJ, Misamore G, Snead DS, Denton P. The impact of preoperative smoking habits on the results of rotator cuff repair. J Shoulder Elbow Surg 2004; 13(2): 129-32. [http://dx.doi.org/10.1016/j.jse.2003.11.002] [PMID: 14997086]

[43] Kelley MJ, McClure PW, Leggin BG. Frozen shoulder: evidence and a proposed model guiding rehabilitation. J Orthop Sports Phys Ther 2009; 39(2): 135-48.

[http://dx.doi.org/10.2519/jospt.2009.2916] [PMID: 19194024]

[44] Warrender WJ, Brown OL, Abboud JA. Outcomes of arthroscopic rotator cuff repairs in obese patients. J Shoulder Elbow Surg 2011; 20(6): 961-7.

[http://dx.doi.org/10.1016/j.jse.2010.11.006] [PMID: 21324416] 
[45] Lapner PC, Su Y, Simon D, El-Fatori S, Lopez-Vidriero E. Does the upward migration index predict function and quality of life in arthroscopic rotator cuff repair? Clin Orthop Relat Res 2010; 468(11): 3063-9. [http://dx.doi.org/10.1007/s11999-010-1457-7] [PMID: 20607465]

[46] Lawrence RL, Braman JP, Staker JL, Laprade RF, Ludewig PM. Comparison of 3-dimensional shoulder complex kinematics in individuals with and without shoulder pain, part 2: glenohumeral joint. J Orthop Sports Phys Ther 2014; 44(9): 646-55. B641-3 [http://dx.doi.org/10.2519/jospt.2014.5556] [PMID: 25103132]

[47] Escamilla RF, Yamashiro K, Paulos L, Andrews JR. Shoulder muscle activity and function in common shoulder rehabilitation exercises Sports Med 2009; 39(8): 663-85. [http://dx.doi.org/10.2165/00007256-200939080-00004] [PMID: 19769415]

[48] Michener LA, McClure PW, Karduna AR. Anatomical and biomechanical mechanisms of subacromial impingement syndrome. Clin Biomech (Bristol, Avon) 2003; 18(5): 369-79. [http://dx.doi.org/10.1016/S0268-0033(03)00047-0] [PMID: 12763431]

[49] Flatow EL, Soslowsky LJ, Ticker JB, et al. Excursion of the rotator cuff under the acromion. Patterns of subacromial contact. Am J Sports Med 1994; 22(6): 779-88. [http://dx.doi.org/10.1177/036354659402200609] [PMID: 7856802]

[50] Dvir Z, Berme N. The shoulder complex in elevation of the arm: a mechanism approach. J Biomech 1978; 11(5): 219-25. [http://dx.doi.org/10.1016/0021-9290(78)90047-7] [PMID: 711770]

[51] Muraki T, Aoki M, Uchiyama E, Miyasaka T, Murakami G, Miyamoto S. Strain on the repaired supraspinatus tendon during manual traction and translational glide mobilization on the glenohumeral joint: a cadaveric biomechanics study. Man Ther 2007; 12(3): 231-9. [http://dx.doi.org/10.1016/j.math.2006.06.017] [PMID: 16973401]

[52] Johnson AJ, Godges JJ, Zimmerman GJ, Ounanian LL. The effect of anterior versus posterior glide joint mobilization on external rotation range of motion in patients with shoulder adhesive capsulitis. J Orthop Sports Phys Ther 2007; 37(3): 88-99. [http://dx.doi.org/10.2519/jospt.2007.2307] [PMID: 17416123]

[53] Lawrence RL, Braman JP, Laprade RF, Ludewig PM. Comparison of 3-dimensional shoulder complex kinematics in individuals with and without shoulder pain, part 1: sternoclavicular, acromioclavicular, and scapulothoracic joints. J Orthop Sports Phys Ther 2014; 44(9): 636-5. A631-638 [http://dx.doi.org/10.2519/jospt.2014.5339] [PMID: 25103135]

[54] Ludewig PM, Reynolds JF. The association of scapular kinematics and glenohumeral joint pathologies. J Orthop Sports Phys Ther 2009; 39(2): 90-104. [http://dx.doi.org/10.2519/jospt.2009.2808] [PMID: 19194022]

[55] Reinold MM, Escamilla RF, Wilk KE. Current concepts in the scientific and clinical rationale behind exercises for glenohumeral and scapulothoracic musculature. J Orthop Sports Phys Ther 2009; 39(2): 105-17. [http://dx.doi.org/10.2519/jospt.2009.2835] [PMID: 19194023]

[56] Thomopoulos S, Williams GR, Gimbel JA, Favata M, Soslowsky LJ. Variation of biomechanical, structural, and compositional properties along the tendon to bone insertion site. J Orthop Res 2003; 21(3): 413-9.

[57] Kim DH, Millett PJ, Warner JJ, Jobe FW. Shoulder injuries in golf. Am J Sports Med 2004; 32(5): 1324-30. [http://dx.doi.org/10.1177/0363546504267346] [PMID: 15262661]

(C) Kokmeyer et al.; Licensee Bentham Open.

This is an open access article licensed under the terms of the Creative Commons Attribution-Non-Commercial 4.0 International Public License (CC BY-NC 4.0) (https://creativecommons.org/licenses/by-nc/4.0/legalcode), which permits unrestricted, non-commercial use, distribution and reproduction in any medium, provided the work is properly cited. 